\title{
THE USE OF THE SERUM OPACITY REACTION IN THE TYPING OF GROUP-A STREPTOCOCCI
}

\author{
W. R. Maxted, Jean P. Widdowson, Cherry A. M. Fraser, \\ LYN C. Ball AND D. C. J. BasseTt \\ Cross-Infection Reference Laboratory, Central Public Health Laboratory, \\ Colindale Avenue, London, NW9 $5 H T$
}

\section{Plate III}

Some group-A streptococci cause the appearance of opacity in horse serum (Ward and Rudd, 1938). The production of the opacity factor (OF) is confined to members of certain serotypes (Keogh and Simmons, 1940; Gooder, 1961), and the OF of each serotype is antigenically specific (Top and Wannamaker, 1968a). Widdowson, Maxted and Grant (1970) confirmed the serological specificity of the OF and showed that it corresponded exactly to that of the $M$ type of the streptococcus that produces it. The examination of a limited number of strains of each M type (Widdowson et al., 1970; and our unpublished observations) suggested that OF is produced by all members of 16 welldefined $M$ types, and by a number of other types not so far established by international agreement.

We have now made a more sytematic examination of the distribution of OF among strains of group-A streptococci sent to us for typing, and have investigated the use of the serum opacity reaction (SOR), and of its neutralisation by specific antisera, in routine typing and as a means of indentifying hitherto unrecognised streptococcal serotypes.

\section{MATERIALS AND METHODS}

\section{Streptococci}

Strains used to produce antisera to OF in rabbits were the standard type strains used in the Streptococcus Reference Laboratory for the production of $\mathbf{M}$ antisera. Other strains sent to us for type identification from numerous laboratories were used in studies of the distribution of OF.

\section{Cultural methods}

Oxoid Todd-Hewitt Broth with the addition of 1 per cent. Neopeptone was seeded with a loopful of growth from solid medium and incubated overnight at $37^{\circ} \mathrm{C}$. These cultures were used for the detection both of OF and of $M$ antigen.

\section{Typing technique}

The methods used in the Streptococcus Reference Laboratory for the preparation of typing sera and for $M$ and $T$ typing are those described by Williams (1958). $M$ antigen was

Received 26 June 1972; accepted 20 July 1970.

J. MED. MCROBIOL.-VVL. 6 (1973) 
usually detected by a precipitin test in capillary tubes (Swift, Wilson and Lancefield, 1943) but tests were also done by the double-diffusion method (Ouchterlony, 1949) in 1 per cent. Ion Agar (Oxoid) gel slides.

\section{Horse serum}

A supply of horse serum (No. 2. Recalcified, heated) was received each week from Messrs Burroughs Wellcome, Beckenham, England. Not all batches were equally good for use in the serum opacity test. Each bottle of serum was tested by the tube and the slide technique against culture supernatants known to have active OF, and good batches were reserved for this investigation.

\section{Antisera to opacity factor}

Three of these sera, prepared against cell-wall fragments of streptococci of M-types 2, 4 and 25 were those used by Widdowson $e t$ al. (1970). Other sera were unabsorbed M-typing sera, made in the conventional manner (Williams) by the Streptococcus Reference Laboratory, that had been found also to contain antibody that inhibited the SOR of the homologous strain.

Specific inhibitory antisera were available for the OF of types $2,4,9,11,22,25,28,48$, $49,58,59,62$ and 63, and for PS346, a provisional new M type awaiting recognition by the International Subcommittee on the Taxonomy of Streptococci (Bassett, unpublished). All these antisera had been tested against the full complement of OF-positive supernatants (Maxted, Widdowson and Fraser, 1973) and shown to be specific in their ability to inhibit the opacity reaction of the vaccine strain, and of other strains of the same $M$ type, but not of other types.

\section{Serum opacity reaction}

In the tube method, culture supernates or hot-acid (" Lancefield ") extracts of cells (Swift, Wilson and Lancefield) were tested as described by Widdowson et al. (1970). In the slide method, tests were done by mixing 1 volume of 2 per cent. Ion Agar with 1 volume of horse serum to which 1 in 5000 thiomersal $(\mathrm{w} / \mathrm{v})$ had been added, and pouring approximately $5 \mathrm{ml}$ of the mixture on to $2 \mathrm{in} . \times 2$ in. $(5 \mathrm{~cm} \times 5 \mathrm{~cm})$ glass slides. Before use, the agar slides were dried in a $37^{\circ} \mathrm{C}$ incubator for $15-20 \mathrm{~min}$. A loopful ( $2 \mathrm{~mm}$ diameter) of culture supernate or Lancefield extract was put on to the serum agar surface and the slide incubated in a moist chamber at $37^{\circ} \mathrm{C}$ overnight.

\section{Type-specific inhibition of the serum opacity reaction}

Tube method. To $0.1 \mathrm{ml}$ of culture supernate of the strain under test was added $0.02 \mathrm{ml}$ of antiserum at a dilution previously shown to be inhibitory for the OF of the homologous strain. The tubes were shaken and incubated for $30 \mathrm{~min}$. at $37^{\circ} \mathrm{C} ; 1 \mathrm{ml}$ of horse serum was then added to each tube and the tubes were shaken and incubated at $37^{\circ} \mathrm{C}$ overnight. Controls of horse serum without antiserum, and of horse serum without OF, were always included. The tubes were read visually, or the optical density at $475 \mathrm{~nm}\left(\mathrm{~A}_{475}\right)$ was read, after dilution with an equal volume of saline, on a Unicam SP 600 spectrophotometer (Widdowson et al., 1970). Depression of the $A_{475}$ by 0.1 or more in comparison with the control was taken as evidence of inhibition.

Solid agar method. Equal volumes of 2 per cent. Ion Agar and horse serum were mixed, and to $6 \mathrm{ml}$ of the mixture $1.2 \mathrm{ml}$ of active OF supernate was added. After thoroughly mixing, this was poured on to a glass slide. The slides were dried for $20 \mathrm{~min}$. at $37^{\circ} \mathrm{C}$. A loopful ( $2 \mathrm{~mm}$ diameter) of antiserum against OF, either undiluted or in a series of two-fold dilutions for titration, was put on to the agar surface. The slides were incubated overnight in a moist chamber. The reaction of the $\mathrm{OF}$ and the horse serum produced an opaque background, and clear areas of inhibition were seen when the serum had inhibitory activity. 


\section{RESULTS \\ Distribution of opacity factor among group-A streptococci of various $M$ types}

Table I summarises existing information about the distribution of $\mathrm{OF}$ among the various $M$ types of group-A streptococci. This information was gathered in the course of other investigations and was based on the examination of a rather small number of strains, particularly of rarer types. Nevertheless, it suggested that OF production was a constant character of $16 \mathrm{M}$ types but not of 32 others.

We performed the serum opacity reaction on 1648 strains of group-A streptococci received consecutively for typing. For this purpose we used the 50-ml Todd-Hewitt broth cultures prepared for $\mathrm{M}$ typing. Earlier experience had indicated that the OF would be present in both the supernate and the Lancefield extract, and this was in general confirmed in a series of parallel

TABLE I

Presence or absence of opacity factor in different $M$ types of streptococci

\begin{tabular}{cc}
\hline Opacity factor & M type number \\
\hline present & $2,4,9,11,13,22,25,28,48,49,58,59,60,61,62,63$ \\
\hline absent & $1,3,5,6,12,14,15,17,18,19,23,24,26,29,30,31$, \\
& $33,36,37,39,41,43,46,47,50,51,52,53,54,55,56,57$ \\
\hline
\end{tabular}

All members of the $M$ types shown behave similarly in the serum opacity reaction.

tests. Sometimes, however, a strain would persistently give an active supernate and a weak extract; but occasionally the opposite was found. Tests on the supernate were a more convenient means of screening large numbers of cultures and were used throughout this survey. When an unexpected result was obtained, however, the acid extract was also tested. The first 300 cultures were examined both by the tube method and the slide method, and identical results were obtained. For the remainder of the tests only the slide method was used (fig. 1).

Of the 1648 strains tested, 1022 ( 62 per cent.) were typable with the available $\mathrm{M}$ antisera, and included members of 24 different $\mathrm{M}$ types (table II). In every case, all members of the same $M$ type gave either a positive or a negative serum opacity reaction, and all the reactions corresponded to those given in table I.

The remaining 626 strains could not be typed with $M$ antisera but all except two of them were typable by the T-agglutination method. Several of the large groups of strains without a detectable $M$ antigen but with a common agglutination pattern, e.g., 3, 13, 3/13/B3264, 12, 28, 25/Imp 19, could, however, be subdivided into SOR-positive and SOR-negative strains, and this proved epidemiologically useful on a number of occasions. The fact that 460 of the 
$626 \mathrm{M}$-untypable strains were SOR positive is in conformity with earlier observations (Gooder; Top and Wannamaker, 1968b) that it was mainly strains for which $\mathrm{M}$ antisera had not been successfully prepared that formed OF.

TABLE II

Serological typing and the serum opacity reaction (SOR) of 1648 strains of group-A streptococci

\begin{tabular}{|c|c|c|c|c|c|c|c|}
\hline$\underset{\text { reaction }}{\mathrm{T}}$ & $\underset{\text { reaction }}{\mathrm{M}}$ & SOR* & $\begin{array}{l}\text { Number of } \\
\text { strains }\end{array}$ & $\underset{\text { reaction }}{\mathrm{T}}$ & $\underset{\text { reaction }}{\mathbf{M}}$ & SOR* & $\begin{array}{l}\text { Number of } \\
\text { strains }\end{array}$ \\
\hline 1 & 1 & - & 111 & & $(12$ & - & 156 \\
\hline 2 & 2 & + & 10 & & 22 & + & 188 \\
\hline & 3 & - & 13 & 12 & 62 & + & 11 \\
\hline 3 & - & - & 27 & & - & - & 7 \\
\hline & & \pm & 22 & & $\overline{14}$ & + & 31 \\
\hline 13 & & t & $\begin{array}{l}11 \\
120\end{array}$ & 14 & 14 & $\overline{-}$ & 15 \\
\hline & 3 & - & 1 & $15 / 17 / 23 / 47$ & 19 & - & 3 \\
\hline & 33 & - & 7 & 18 & 18 & -. & 8 \\
\hline $3 / 13 / \mathrm{B} 3264$ & 41 & - & 13 & 22 & 22 & + & 8 \\
\hline & - & I & $\begin{array}{l}52 \\
17\end{array}$ & 25/IMP 19 & 25 & \pm & 10 \\
\hline & 4 & + & 138 & & - & + & $\begin{array}{c}42 \\
199\end{array}$ \\
\hline 4 & 29 & - & 1 & & 28 & + & 103 \\
\hline & - & $\bar{t}$ & $\frac{1}{2}$ & 28 & - & $\overline{1}$ & 15 \\
\hline $5 / 27 / 44$ & 5 & - & 47 & 49 & 49 & $t$ & $\stackrel{\circ}{15}$ \\
\hline & & + & 50 & 55 & 55 & - & 2 \\
\hline 6 & - & $\overline{-}$ & 62 & 58 & 58 & + & 69 \\
\hline 9 & 9 & + & 34 & 3875 & $\overline{-}$ & + & $\begin{array}{l}1 \\
3\end{array}$ \\
\hline & & $\bar{t}$ & $\begin{array}{r}4 \\
11\end{array}$ & Untypable & 二 & - & 1 \\
\hline 11 & & + & 6 & & & & \\
\hline
\end{tabular}

$*-=$ No opacity in horse serum; $+=$ opacity in horse serum.

$\dagger \mathrm{T}$ reaction given by members of an $M$ type that is not yet recognised internationally.

\section{Value of the opacity reaction in routine typing}

In the combined $M$ and T typing system (Williams and Maxted, 1953) it is customary to carry out the T-agglutination test first, and to set up M-precipitation tests only with antisera for $M$ antigens known to occur in strains with the T-agglutination pattern found. $\mathrm{M}$ antisera are scarce and difficult to prepare, and a preliminary classification of strains into SOR negative and SOR positive will in a number of cases reduce the number of $M$ antisera used in typing. For example, the series of $M$ types that share the $\mathrm{T} 4$ antigen includes four that are SOR positive and four that are SOR negative (table III); in this case knowledge of the SOR of the strain halves the number of sera that need to be used. The four SOR-positive types can also be typed with the corresponding anti-OF sera by specific inhibition of opacity production (fig. 2). This is useful, because $M$ antisera for these four types are often weak and unsatisfactory for $M$ typing by the capillary precipitation test.

An inspection of table II will show several other situations in which the 


\section{OPACITY REACTION IN STREPTOCOCCAL TYPING}

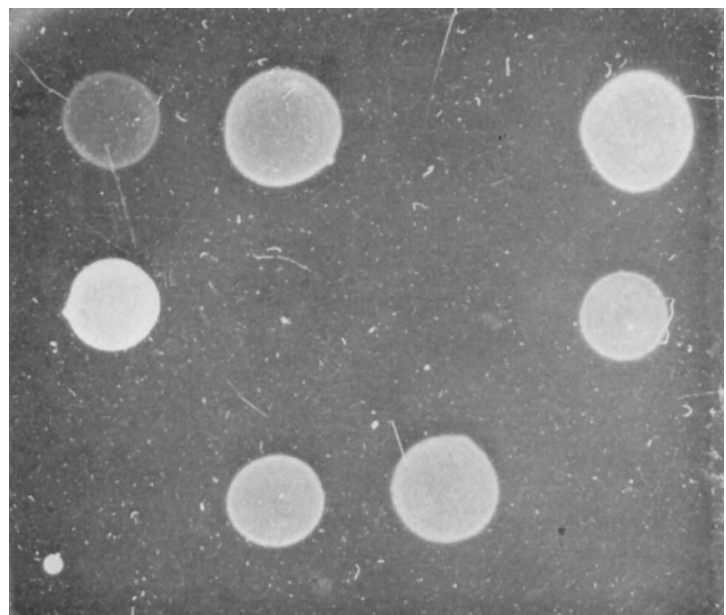

FIG. 1.-Serum opacity reaction (slide method). The supernate of overnight broth cultures of 12 different streptococci tested on horse serum-agar slides. Five are negative and seven positive. $\times 1 \cdot 5$.

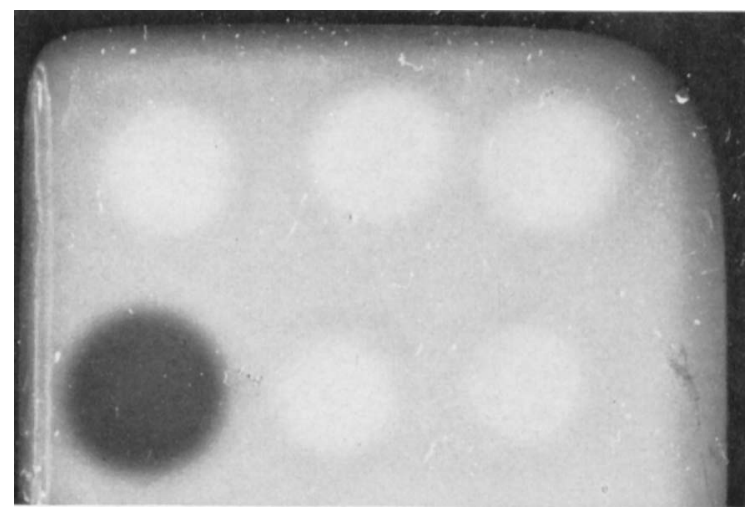

FIG. 2.-Type-specific inhibition of the serum opacity reaction. Drops of rabbit antiserum against opacity factor were placed on the surface of horse-serum agar in which the opacity factor of a type 63 streptococcus had been incorporated. Clear area $=$ inhibition of opacity reaction; areas of slightly increased opacity indicate where other drops of serum were placed. Top row ( $($ to R): antisera against types 4,28 , and 48 which share the T-antigen 4 with type 63, but have serologically different opacity factors. Bottom row ( $\mathrm{L}$ to $\mathrm{R}$ ): antisera against type 63 (inhibition), and types 2 and 48 (controls). $\times 1.5$. 
SOR will assist typing by reducing the number of $M$ antisera that need to be used.

\section{Use of the serum opacity reaction for the investigation of anomalous typing results}

The serological typing of group-A streptococci by a combination of the T-agglutination and M-precipitation methods presents occasional technical difficulties and errors occur. In these circumstances the serum opacity reaction has proved helpful.

From time to time strains have been encountered that have the $\mathrm{T}$ reaction $5 / 27 / 44$ and give a poor precipitation reaction with the type-5 $\mathrm{M}$ antiserum.

TABLE III

Serum opacity reaction (SOR) of members of different $M$ types sharing the T4 antigen

\begin{tabular}{ccc}
\hline M antigen & $\begin{array}{c}\text { Serum opacity } \\
\text { reaction }\end{array}$ & $\begin{array}{c}\text { Inhibition of SOR only by antiserum } \\
\text { against opacity factor of M type }\end{array}$ \\
\hline 4 & + & 4 \\
24 & - & $\cdots$ \\
26 & - & $\cdots$ \\
29 & - & $\cdots$ \\
46 & + & 48 \\
48 & + & 60 \\
60 & + & 63 \\
63 & + & \\
\hline
\end{tabular}

This is an excellent antiserum, but our results suggested that these strains were in fact poorly precipitating members of $M$ type 5 . However, this type is invariably SOR negative and the strains under investigation gave a positive opacity test. The fact that these strains did not belong to $M$ type 5 was subsequently confirmed by showing that absorption of the type-5 $\mathrm{M}$ antiserum with them did not remove the M5 antibody but removed the antibody responsible for the reaction of the anomalous strains with the antiserum.

A similar situation was observed with two strains that reacted with M41 antiserum but gave a positive opacity reaction. Precipitation tests were therefore set up in gel and showed that the reaction with this antiserum was not due to type $41 \mathrm{M}$ antigen. Antisera for this type prepared in various laboratories have often given non-specific reactions that are difficult to eliminate (Potter et al., 1968; M. D. Moody, personal communication).

Type 49, which is an OF-positive type, has often proved difficult to identify (Maxted, Fraser and Parker, 1967); M-typing sera are generally weak, and some reliance is placed on the specific T-agglutination reaction for this type. We received six strains from the Sudan and one from Nigeria that were agglutinated by the T49 antiserum and gave a weak M-precipitation reaction for the type. They were, however, SOR negative. Again, tests in gel confirmed that the precipitation reaction was not specific. 
In these cases, the routine performance of the opacity reaction drew attention to potential errors in type identification and led to the detection and elimination of non-specific factors in the typing sera.

The opacity reaction may also be of value in identifying an $M$ type when the strains under examination form $M$ antigen only in small amount. Sixteen strains of group-A streptococci were isolated from boys in a school where tonsillitis was common. All were agglutinated by the T12 antiserum, but only five were $12 \mathrm{M}$ positive. Some of the remainder gave a feeble reaction with M22 antiserum in the capillary precipitation test but others were untypable. However, the 12M strains were SOR negative and all the remainder were SOR positive. Therefore, double-diffusion tests with type-22 $\mathrm{M}$ antiserum were set up with extracts of all the SOR-positive cultures and a positive reaction was obtained in every case. Antisera to type- 22 OF also inhibited opacity production by the strains and identified the cultures as specificially as did the M-precipitation test.

\section{Use of the serum opacity reaction for the identification of new $M$ types}

Finally, the SOR may be useful for the identification of new $M$ types and of types for which no $M$ antiserum is available.

Maxted and Valkenburg (1969) were able to recognise M-type 62 in this way long before $M$ antisera that gave a specific precipitin reaction had been prepared. They observed the replacement of M-type 12 (SOR negative) in the population of the village of Voorhout by an SOR-positive strain without a detectable $M$ antigen and produced evidence that the new strain was a variant of M-type 12. The new type was first recognised by means of the bactericidal test, but precipitating antiserum proved difficult to make, and for some time these strains were identified in routine typing by inhibition of opacity with an anti-OF serum.

More recently, one of us (D. C. J. B.) investigated a large number of strains from cases of streptococcal pyoderma in Trinidad; many of them gave a strong type-4 agglutination reaction but failed to react with any of the available $M$ antisera and a positive SOR was common. Attempts to produce an $M$ antiserum by immunisation of rabbits with a representative strain (SF2) were ultimately successful, and the type is now recognised internationally as type 63 . Early bleedings of the rabbits produced sera that were active inhibitors of the OF of the vaccine strain, but not of that of other known M types with the T4 antigen. These sera were used to screen 179 isolates of T4 strains from Trinidad for inhibition of the SOR, and 17 similar strains were identified. After continuing the immunisation for some months a satisfactory M-precipitating serum for type 63 was obtained and the identity of the 17 strains was confirmed.

\section{Discussion}

The streptococcal OF is of interest because of its close association with $\mathbf{M}$ protein. The $\mathrm{M}$ antigens of SOR-positive $\mathrm{M}$ types contain a high proportion 
of large-molecular-weight material not found in the M protein of SOR-negative types (Widdowson et al., 1971). This difference in the nature of the M protein may account for the poor antigenicity of SOR-positive streptococci when used for the production of $\mathrm{M}$ antisera. It is precisely among such strains that any additional aid to type identification is useful.

The demonstration of OF in the supernate of broth cultures of streptococci that cannot be $M$ typed is good evidence that they do have an $M$ antigen even if it is not detectable with the available antisera. Keogh and Simmons (1940) used OF production as one of a number of cultural markers that were consistently found among certain " types" of streptococci identified by agglutinationtyping. Recently, the production of nicotinamide adenine dinucleotide glycohydrolase (NADG) and of OF has been used as a method of sybtyping group-A streptococci after preliminary sorting according to T type (Ofek et al., 1971), but this gave a precise identification only for M-type 60, the one $M$ type that produced serum opacity factor but no NADG.

The antigenic specificity of the OF in each $M$ type provides us with an even more valuable use for the SOR. The bactericidal test, which is commonly used to confirm doubtful typing results or to establish the existence of new types, is time-consuming and difficult to perform. Specific inhibition of opacity appears to provide a convenient substitute that can be used in the identification of about one-third of the $M$ types.

The examples reported here, in which the serum opacity reaction supported the typing result in batches of strains in which the serological typing is "difficult", indicated an error in M typing, or led to the early recognition of a new type, may promote a more general use of the reaction in streptococcal serology.

\section{SUMMARY}

A large collection of group-A streptococci was examined for the production of opacity in horse serum and for the presence of $\mathrm{M}$ and $\mathrm{T}$ antigens. Opacity production is a constant character of certain $\mathbf{M}$ types and is consistently absent from the rest. Testing for opacity production is a valuable addition to the serological typing procedure especially if it is carried out first. It has proved useful in (1) reducing the number of tests with $M$ antisera that have to be set up and (2) drawing attention to errors in $M$ typing due to the presence of crossreacting precipitins in typing sera.

The serological specificity of the opacity factor corresponds to that of the $M$ antigen. Inhibition of opacity production therefore provides a useful alternative method of typing strains that form the opacity factor. $M$ antisera for opacity-producing serotypes are often of poor quality and difficult to prepare. In these circumstances, the opacity inhibition test has proved useful for preliminary identification of new $\mathbf{M}$ types of streptococci.

\section{REFERENCES}

GOODER, H. 1961. Association of a serum opacity reaction with serological type in Streptococcus pyogenes. J. Gen. Microbiol., 25, 347. 
KEOGH, E. V., AND Simmons, R. T. 1940. Cultural methods as an aid in type differentiation of group A haemolytic streptococci. J. Path. Bact., 50, 137.

Maxted, W. R., Fraser, Cherry A. M., AND Parker, M. T. 1967. Streptococcus pyogenes, type 49. A nephritogenic streptococcus with a wide geographical distribution. Lancet, 1,641 .

MAXTED, W. R., AND Valkenburg, H. A. 1969. Variation in the M-antigen of group A streptococci. J. Med. Microbiol., 2, 199.

Maxted, W. R., Widdowson, Jean P., and Fraser, Cherry A. M. 1973. Antibody to streptococcal opacity factor in human sera. J. Hyg., Camb., 71, in press.

Ofek, I., Fleiderman, S., Bergner-Rabinowitz, Sonya, and Ginsberg, I. 1971. Application of enzyme production properties in subtyping of group A streptococci according to T type. Appl. Microbiol., 22, 748.

OUCHTERLONY, O. 1949. Antigen-antibody reaction in gels. Acta path. microbiol. scand., 26, 507.

Potter, Elizabeth V., Moran, A. F., Poon-King, T., and Earle, D. P. 1968. Characteristics of beta hemolytic streptococci associated with acute glomerulonephritis in Trinidad, West Indies. J. Lab. Clin. Med., 71, 126.

Swift, H. F., Wilson, A. T., AND LanCefield, RebeCCA C. 1943. Typing group A hemolytic streptococci by $\mathrm{M}$ precipitin reactions in capillary pipettes. J. Exp. Med., 78, 127.

TOP, F. H., JR, AND WANNAMAKER, L. W. 1968a. The serum opacity reaction of Streptococcus pyogenes: frequency of production of streptococcal lipoproteinase by strains of different serological types and the relationship to M protein production. J. Hyg., Camb., 66, 49.

ToP, F. H., JR, AND WanNamaker, L. W. 1968b. The serum opacity reaction of Streptococcus pyogenes. The demonstration of multiple, strain-specific lipoproteinase antigens. J. Exp. Med., 127, 1013.

Ward, H. K., AND RudD, G. V. 1938. Studies on haemolytic streptococci from human sources. I. The cultural characteristics of potentially virulent strains. Aust. J. Exp. Biol. Med. Sci., 16, 181.

Widdowson, Jean P., Maxted, W. R., ANd Grant, Doris L. 1970. The production of opacity in serum by group A streptococci and its relationship with the presence of $M$ antigen. J. Gen. Microbiol., 61, 343.

Widdowson, Jean P., Maxted, W. R., Grant, Doris L., and Pinney, Alison M. 1971. The relationship between M-antigen and opacity factor in group A streptococci. J. Gen. Microbiol., 65, 69.

Williams, R. E. O. 1958. Laboratory diagnosis of streptococcal infections. Bull. Wld Hlth Org., 19, 153.

Williams, R. E. O., AND MAXTED, W. R. 1953. The type classification of Streptococcus pyogenes. Atti VI Int. Congr. Microbiol., 1, 46. 